\title{
CONTINUOUS DEPENDENCE FOR SOLUTIONS TO 2-D BOUSSINESQ SYSTEM CHANNEL FLOW
}

\author{
YUANFEI LI AND CHANGHAO LIN
}

Abstract. This paper considers the 2-D Boussinesq system in a semi-infinite channel. By making use of the earlier work of [19] and some Soblev inequalities, the continuous dependence on the coefficient of the system is obtained. The authors also show how to bound the total energy.

Mathematics subject classification (2010): 35K05,35K20,35K55.

Keywords and phrases: Boussinesq equations, Continuous dependence, Channel flow.

\section{REFERENCES}

[1] H. Abidi And T. HMidi, On the global well-posedness for Boussinesq system, J. Differ. Equ., 233, (2007), 199-220.

[2] D. ADHIKARI, C. CAO AND J. WU, The 2-D Boussinesq equations with vertical viscosity and vertical diffusivity, J. Differ. Equ., 249, (2010), 1078-1088.

[3] D. AdhiKARI, C. CAO AND J. Wu, Global regularity results for the2DBoussinesq equations with vertical dissipation, J. Differ. Equ., 251, (2011), 1637-1655.

[4] B.A. Boley, Some observations on Saint-Venant's principle, in: Proc. 3rd US Nat, Congr. Appl. Mech., ASME, New York, (1958), 259-264.

[5] J.R. CANNON AND D. ZaChMANn, Parameter determination in parabolic partial differential equations from overspecified boundary data, Internat.J.Engrg.Sci., 20, (1982), 779-788.

[6] Ch. CaO AND J. Wu, Global Regularity for the Two-Dimensional Anisotropic Boussinesq Equations with Vertical Dissipation, Arch. Rational Mech. Anal., 208,(2013), 985-1004.

[7] D. CHAE, Global regularity for the 2-D Boussinesq equations with partial viscosity terms, Adv.Math., 203, (2006), 497-513.

[8] D. Chat, S. K. Kim AND H.S. NAm,Local existence and blow-up criterion of Hölder continuous solutions of the Boussinesq equations, Nagoya Math. J., 155, (1999), 55-80.

[9] J. Cheng AND S. LI, Global weak solutions and regularity for two-dimensional Boussinesq equations with partial disspation and thermal diffusivity, J. Math. Anal.Appl., 428, (2015), 794-803.

[10] C.H. Hardy, J.E. Littlewood and G. Polya, Inequalities, Cambridge Univ, Press, 1953.

[11] C.O. Horgan, Plane steady flows and energy astimates for the Niver-stokes equations, Arch.Rat.Mech.Anal.,68(1978),359-381.

[12] T.Y. Hou AND C. LI, Global well-posedness of the viscous Boussinesq equations, Discrete Contin.Dyn.Syst., 12, (2005), 1-12.

[13] J. LEE AND J.C. Song, Spatial decay bounds in a linearized magnetohydrodynamics channesl flow, Communications on Pure and Applied analysis, 12, (2013), 1349-1361.

[14] C. Lin, Spatial decay estimates and energy bounds for the Stokes flow equations, Stability Appl. Anal. Contin. Media., 2, (1992), 249-264.

[15] C. Lin AND L. E. PAYNE,Spatial decay bounds in the channel flow of an incompressible viscous fluid, Math. Model. Meth., 6, (2004), 795-818.

[16] C. Lin AND L. E. PAYNe,Phragmen-Lindeöf type results for second order quasilinear parabolic equations in $\mathbb{R}^{2}$, A angew Math Phys., 45, (1994), 294-311.

[17] C. Lin AND L. E. PAYNE,Spatial decay estimates and energy bounds for the Stokes flow equation, SAACM.2, (1992), 249-264. 
[18] Y.LiU AND C. Lin,Spatial decay bounds in time dependent pipe flow of an incompressible viscous fluid, SIAM J. Appl. Math., 65, (2005), 458-475.

[19] Y. LIU, YF. LI, YW. LIN AND ZH. YAO, Spatial decay bounds for the channel flow of the Boussinesq equations, J.Math.Anal.Appl., 381, (2011), 87-109.

[20] A.J. MAJdA AND A.L. BertozZI, Vorticity and Incompressible Flow, Cambridge University Press, Cambridge., 2001.

[21] A.J. MAJDA, Introduction to PDEs andWaves for the Atmosphere and Ocean, Courant Lecture Notes in Mathematics.,9.AMS/CIMS,(2003).

[22] D.S. Mitronovic, Analytical Inequalities, Springer-Verlag., 1970.

[23] L.E. PAYNEN,Uniqueness criteria for steady state solutions of the Navier-Stokes equation, in: Simpos. Internaz, Appl. Anal. Fis. Mat., Cagliari-Sassari, 1964, Edizioni Cremonse, Rome, (1965), 130-153.

[24] L.E. PAYNE, Uniqueness and continuous dependence criteria for the Navier-Stokes equations, Rocky Mountain J. Math. 2, (1971), 641-660.

[25] L.E. Payne AND G.A. PhilipPin, Pointwise bounds and spatial decay estimates in heat conduction problems, Math. Models Methods Appl. Sci., 5, (1995), 755-775.

[26] L.E. Payne, P.W. Schaefer AND J.C. Song, Growth and decay results in heat conduction problems with nonlinear boundary conditions, Nonlinear Anal., 33, (1999), 269-286.

[27] J.Pedlos Ky, Geophysical Fluid Dyanmics, Springer, New York., 1987.

[28] J. C. Song, Improved decay estimates in time-dependent Stokes flow, J. Math. Anal. Appl., 288, (2003), 505-517.

[29] J. C. Song, Improved spatial decay bounds in the plane Stokes flow, Appl. Math. Mech., 30, (2009), 833-838. 